DOI: $10.17805 / z p u .2016 .3 .6$

\title{
Ценностный выбор российского общества как проблема культурной самоидентификации
}

\author{
О. А. ЖУКОВА \\ (НАЦИОНАЛЬНЫЙ ИССЛЕДОВАТЕЛЬСКИЙ УНИВЕРСИТЕТ \\ «ВЫСШАЯ ШКОЛА ЭКОНОМИКИ», Г. МОСКВА)
}

Статья посвящена проблеме исторического самопознания современного российского общества. Цивилизационное самоопределение нации, считает автор, формируется в результате освоения отечественной истории, извлечения уроков из социальных катастроф XX в. Наследование социального опыта прошлого возможно как актуализация культурных ценностей, выработанных в рамках отечественных религиозных, художественных, политических традиций. Российскому обществу следует расширять дискурсивные практики культурно-исторического знания, а вместе с тем и публичное обсуждение истории и культуры. В статье рассматриваются два вектора развития этой ситуации - образовательный и культурный.

Особенно остро стоит вопрос о понимании и представлении молодого поколения о самих себе, о ценностном наполнении их жизненного опыта, об отношении к истории своей страны и наследию национальных культур. Автор приводит результаты социологических исследований, которые проводились им в течение шести лет (2006-2012 гг.) со студенческой аудиторией первого курса Института управления и экономики промышленных предприятий Национального исследовательского технологического университета «Московский институт стали и сплавов». Результаты исследования показывают, что студенческая молодежь продолжает воспринимать историческое прошлое страны как живую часть культурного опыта современного российского социума, признавая духовное и художественное наследие своеобразной гарантией развития исторического самосознания - условием движения к будущему.

Эта тенденция в последнее десятилетие развивается с общей линией государственной культурной политики по восстановлению исторической преемственности и сохранению культурного наследия. Анализируется политика государства в области образования и культуры, использование современного инструментария мультимедиа в просветительских целях, актуальные формы организации музейно-выставочных пространств, которые становятся интеллектуальными площадками для выработки общенациональной идеи. Споры об интерпретации истории, возможности единого учебника и пр. обозначают болевые точки исторического самочувствия нации.

Ключевые слова: ценностный выбор; российское общество; культурная самоидентификация; культурная память; культурное предание; исторический опыт

\section{ВВЕАЕНИЕ}

иагностированный 3. Бауманом в книге «Индивидуализированное общество»
синдром современного социума, предпочитающего жить без связей с вечно-
стью (Бауман, 2005), обладает множественным эффектом. Не меньшее желание
человек новой информационной эпохи обнаруживает в своем стремлении освобо-
диться от истории, от груза ее духовных традиций и социальных практик и тем са-
мым вытеснить проблемы морали и ответственного поведения за пределы своего
индивидуального и коллективного опыта. Заместительная антиметафизическая
и антиисторическая терапия во имя полной автономной свободы индивида снима-
ет и другую травмирующую современного человека проблему - проблему куль-
турной идентичности, которая неизбежно отягощена не только трудным и энер- 
гозатратным процессом овладения высокими достижениями мысли и духа, но и культурной памятью. Историческая память с ее накопленными веками социальными противоречиями, историческими конфликтами и катастрофами может транслировать большие риски, способные разрушить комфортное существование человека общества потребления и культуры удовольствий.

Обозначенная нами проблема культурной и цивилизационной самоидентификации и ценностного выбора стоит перед складывающейся российской политической нацией. Настоящая проблема обретает реальное жизненное наполнение и не ограничивается сферой философско-теоретического интереса. Запрос на большую философско-культурологическую идею, в основе которой лежит правдивое и аргументированное понимание отечественной истории, будет лишь возрастать. И речь здесь идет не только о «канонической» интерпретации истории для школьников, но в первую очередь о самоопределении российской власти и общества, ставящих перед собой стратегические цели экономического развития, политического и культурного строительства.

В этом смысле любое общество, как и российское сегодня, нуждается в процедуре самообоснования. Будет уместным вспомнить, как на заре великой славы Империи гениальное творение Вергилия «Энеида» стала рукотворным преданием-мифом Рима, заложив основы его политической субъектности и вместе с этим претензии на неоспоримое право доминировать в культурной истории Аревнего мира. В реальном историческом процессе события прошлого и настоящего тесно переплетены - механизм памяти осуществляет селекцию событий постоянно, создавая и пересоздавая культурный миф. Прошлое, спроецированное на экран настоящего, выступает канвой культурного предания, на основе которого составляется рисунок настоящего. Ю. М. Цотман так пишет о механизме культурной памяти: «Каждая культура определяет парадигму того, что следует помнить (то есть хранить), а что подлежит забвению. Последнее вычеркивается из памяти коллектива, и “как бы перестает существовать". Но сменяется время, система кодов, и меняется парадигма памяти-забвения. То, что объявлялось истинно существующим, может оказаться “как бы не существующим” и подлежащим забвению, а несуществовавшее - сделаться существующим и значимым» (Иотман, 2004: 675). Как представляется, в этом процессе припоминания важнейшими интеллектуальными процедурами являются реконструкция и запись культурного предания. В конкретный момент исторического времени нация должна и способна актуализировать культурное предание - заново его прочитывать и понимать.

\section{РОССИЙСКИЙ ОПЫТ \\ ИСТОРИЧЕСКОГО САМОПОЗНАНИЯ}

Приходится признать, что историческое самопознание не является сильной стороной российского общества. Современный человек вообще старается избавиться от бремени истории, явно или неявно избегая труда изучения культурной истории, вследствие чего недооценивает и силу примеров. А именно исторические примеры содержат в себе огромный социализирующий и воспитательный потенциал, формируя систему ценностей личности и общества. Эту нравственно-практическую и интеллектуальную силу примеров подчеркивал выдающийся русский историк Т. Н. Грановский. Говоря об отношении к истории у греков и римлян, Гра- 
новский заметил: «Они верили в могущество примеров» (Грановский, 2010: 434). В подтверждение своей мысли он привел известную сентенцию Цицерона "Historia vero testis temporum, lux veritatis, vita memoriae, magistra vitae, nuntia vetustatis » 1 (там же).

Справедливо утверждать, что российское общество сегодня ощущает явный дефицит общественно значимых прецедентов социально-культурного творчества созидательных образцов общественно-политической, творческой, образовательной, экономической деятельности. Запрос на них только формируется, вследствие чего духовный и интеллектуальный опыт прошлого в полной мере пока не может стать ценностным стержнем строительства культурно-политической нации.

Как в данной ситуации ведут себя государство, профессиональные педагогические и научно-творческие сообщества, религиозные и общественные организации? Как мыслят горизонт своих целей и задач гуманитарий-исследователь и гуманитарий-учитель, какой философский вопрос они адресуют прошлому, чтобы понять настоящее и увидеть контуры будущего для себя и подрастающего поколения? Очевидно, в вопросе к истории всегда содержится желание услышать ответ, который может стать исходным основанием для жизни личности, общества, культуры, нации, государства.

Как представляется, в рамках задачи освоения опыта прошлого и ценностной интериоризации духовно-культурного наследия российскому обществу следует расширять дискурсивные практики культурно-исторического знания (общественные, образовательные, научные), расширяя вместе с тем и публичное пространство обсуждения истории и культуры с целью выработки адекватного языка описания и извлечения смыслов из культурных традиций. Аругими словами, культурную историю разумнее обращать в капитал и использовать его в качестве основы для развития общества.

Однако может возникнуть вопрос: как и почему нашему современнику может быть интересна история России в многосложном переплетении и динамическом развитии духовно-нравственной, интеллектуальной и политической традиций? Первый и главный посыл - преодоление разрыва в наследовании традиций, второй - актуализация процесса преемственности социального и духовного опыта, третий - формирование культуры памяти, которая во многом была репрессирована драматическими событиями социальной истории России в XX в. Россия как субъект исторического творчества и один из главных игроков глобальной современности вынуждена озаботиться своим собственньм культурно-политическим проектом, дав ему историческое обоснование, иными словами, определив место в мировом ансамбле культур, цивилизаций и исторической памяти.

Увы, несмотря на достигнутый уровень всеобщей грамотности, культурно-музейной, библиотечной и электронной доступности к историческим источникам в виде артефактов и документов, а также к огромному количеству популярной и научной литературы, постсоветское общество с трудом преодолевает болезнь, замеченную еще А. С. Пушкиным - леность и нелюбопытство. Вследствие нее многие сюжеты и проблемы российской культурной истории оказываются вне предмета общественно-исторического самопознания и публичной дискуссии, которые крайне необходимы именно как условие выработки национального консенсуса по поводу своей собственной исторической судьбы в прошлом, настоящем 
и будущем. Симптоматично, что российское общество сегодня обременено не столько исторической памятью, сколько драматическим наследством своей истории. Можно даже говорить об определенном синдроме страха перед историей, о желании вытеснить исторические фантомы из своего сознания. Боязнь прошлого можно оправдать психологической самозащитой, но лишь отчасти. Нет другого рецепта преодоления исторических фобий и травм, кроме спокойного и вдумчивого изучения социального и культурного опыта. В противном случае будет постоянно воспроизводиться прогностический сценарий В. О. Ключевского, напоминающего об истории как надзирательнице, которая больно наказывает нерадивых и невежественных, не желающих вдумываться в уроки, ею преподносимые.

В контексте освоения нарративов отечественной истории это означает, что перед современным российским обществом, как и прежде, стоит задача определения культурной и цивилизационной идентичности. История становится своеобразным экраном, демонстрирующим причины «неустройства» общественного бытия и нерешенный вопрос - чем является Россия - Европой, или не Европой. Преодолевая геополитические катастрофы XX в., российское общество стоит перед тем же выбором, который был сформулирован и осознан русскими философами, историками, политиками и писателями: Россия - это страна европейской идентичности (как считали представители русской либерально-консервативной мысли), евразийской (по мнению П. Сувчинского, П. Савицкого, Н. Трубецкого), византийской (К. Аеонтьев, отчасти Г. Флоровский, И. Ильин) или самобытная цивилизация (поздние евразийцы и почвенники)? К этим историософским темам, артикулированным русской мыслью XIX - первой половины XX в., добавились актуальные проблемы политической и культурной истории России советского и постсоветского периода. Среди них: наследие революции, большевизма и коммунизма, Гражданская война, сталинские репрессии, хрущевская оттепель, брежневский застой, горбачевская перестройка и распад СССР, ельцинская эпоха, гайдаровские реформы и приватизация по Чубайсу, чеченские войны, борьба за государственный суверенитет и путинская вертикаль власти, новая архитектоника глобального мира и крымский консенсус.

Споры об интерпретации, о возможности единого учебника, о политике памяти и забвения обозначают болевые точки исторического самочувствия нации, демонстрируя непростой процесс культурной самоидентификации, сопряженный с принятием определенной системы иенностей. Обратим внимание на два вектора развития этой ситуации - образовательный и культурный, тесно между собой взаимодействующие. В первом случае рассмотрим насущный исследовательский и педагогический сюжет - проблему преподавания отечественной истории и культуры в вузах, во втором - опыт реконструкции культурной истории России и актуальные формы ее репрезентации. Будем исходить из тезиса, что предметы историко-культурной направленности имеют не только информационно-образовательную, но и ценностно-воспитательную функцию. Преподавание истории, как и литературы, отечественной и мировой культуры, имеет большое общественное значение. По авторитетному мнению Т. Н. Грановского, университетского педагога, воспитавшего целое поколения русских интеллектуалов, цель изучения истории заключается в том, чтобы стать полезными гражданами и созидательными практиками (Грановский, 2010: 432). 


\section{КУАБТУРНАЯ ИСТОРИЯ РОССИИ В ВУЗЕ: \\ САМОИАЕНТИФИКАЦИЯ СТУАЕНЧЕСКОЙ МОАОАЕЖИ}

Какие же сегодня интеллектуальные стратегии и тактики, какие ценности должны генерировать социальную активность молодежи, помогая ей найти себя и гармонично войти в социум, быть в нем продуктивными индивидами? Специально заметим, что российскому обществу сегодня приходится преодолевать поколенческие разрывы, взятые не в узком значении «отцов и детей», а в широком социально-историческом и культурном плане. Это значительно осложняет процесс консолидации общества в историческую нацию, способную интегрироваться в проект современности, не потеряв своей идентичности. В связи с этим особенно остро стоит вопрос о том, как представляет себя молодое поколение, вопрос о понимании себя, ценностном наполнении жизненного опыта молодежи, об отношении к истории своей страны и наследию национальных культур.

Приведем в качестве примера наш опыт преподавания курса «Ауховные основы русской культуры» в Национальном исследовательском технологическом университете «Московский институт стали и сплавов» (НИТУ МИСиС). Аанный курс, читавшийся с 2006 по 2012 г., преследовал цель расширения культурного кругозора студентов, обучающихся по специальностям как социогуманитарного, так и экономического профиля, повышения их общекультурных и профессиональных компетенций. В методологическую основу лекционного элективного курса был положен ведущий в современном гуманитарном знании и образовании философско-культурологический подход. Настоящий курс предлагал студентам целостный взгляд на феномен культурной истории России в аспекте ее духовно-художественного и интеллектуального наследия, ставил акцент на преемственности исторического опыта и национально-культурных традиций, выявляя смысл и значение русской культуры в контексте мировой истории и ее роль в глобальном проекте современности (Жукова, 2006, 2007, 2008). Проблематика курса выстраивалась вокруг актуальной повестки социокультурной ситуации в России, межконфессионального и культурного диалога.

В течение шести лет (2006-2012 гг.) мы проводили социологические исследования - опросы студентов первого курса Института управления и экономики промышленных предприятий МИСиС. Цель исследований заключалась в составлении социологического портрета молодого поколения, выявлении ценностных ориентаций и культурных предпочтений на примере целевой аудитории будущих экономистов и менеджеров. Предметом исследования выступала культурная самоидентификация российской студенческой молодежи сквозь призму отношения молодого поколения к исторической России, ее духовно-культурному наследию, представлению о себе как о гражданах современной России.

Проблемное поле исследования очерчивалось следующими темами: Культурные традиции России и формирование культурной идентичности человека; Историческое наследие российской цивилизации в опыте современного человека и общества; Русская культура как основа формирования культурно-политической нации; Ауховный фактор в политической, социальной, экономической и культурной жизни России; Национальная культура и национальное государство в глобальном мире; Культурно-политическая стратегия развития России в эпоху глобализации. 
Вопросы анкеты выявляли отношение студентов по нескольким ключевым ценностным позициям.

1. Изучение дисчиплин историко-культурного иикла, посвященньх духовнонравственным традиииям России. Необходимым изучение истории русской культуры в аспекте ее духовных традиций в школе и вузе посчитала треть опрошенных (от 30 до 41\%), при этом доминировали мнения о факультативном характере подобных дисциплин в структуре учебного плана (от 49 до 69\%).

2. История и современность. Связали восприятие современной России с ее историческим прошлым от 70 до $85 \%$ студентов, нашли в истории России события, достойные глубокого уважения и восхищения, от 86 до 98\%.

3. Ауховно-культурное наследие России. Студенты признались, что есть исторические герои, образы которых повлияли на их личное отношение к культуре и истории страны (от 55 до 81\%), что у них есть любимые памятники русской культуры и искусства, вызывающие чувства удивления и восхищения (от 69 до $81 \%$ ).

4. Русская литература и образ начиональной культурьь. Многие из опрашиваемых сочли явно недостаточным свой опыт чтения и изучения русской литературы (от 55 до 79\%). Бо́льшая часть анкетируемых воспринимает русскую культуру скорее не как национальную, а как часть мировой (от 67 до $78 \%$ ).

5. Значение духовного фактора $в$ жизни современного общества. Большинство участников опросов связали экономический успех современной России с духовнонравственным самосознанием нации (от 60 до 75\%). Многие были убеждены, что религиозный опыт является условием формирования нравственного самосознания личности (от 69 до 81\%).

6. Культурные традииии в многонащиональной России. Большинство студентов были согласны с тезисом, что знание и любовь к национальным традициям воспитывают уважение к традициям других культур (от 69 до 82\%). От 47 до 64\% студентов в разные годы высказали мысль, что сохранение православия как культурообразующей традиции исторической России в условиях современности может способствовать укреплению российской государственности и экономическому процветанию страны.

Комментарии к вопросам анкеты выявили широкий спектр мнений, порой противоположных, что отражает драматический процесс самоопределения личности в ходе осмысления исторической судьбы России. Приведем следующие характерные высказывания, сопровождавшие анкетные вопросы: «Будущее и настоящее России зависит от ее прошлого»; «Сложно ответить: не могу сказать, что горжусь историей России. Родину люблю, но слишком много крови»; «Без знания прошлого мы обречены на повторение ошибок»; «Современная Россия без истории и памяти - ничто»; «Прошлое утеряно, так как взят курс на повторение Америки»; «Могущество России обеспечено ее прошлым»; «Наша страна многоконфессиональная, что является проблемой для объединения народов на основе религии»; «Нужно прививать любовь к Богу в рамках всех религиозных традиций»; «Смысл героизма и подвига - жертва, которая равняет маршала и солдата»; «Жаль, что молодые люди мало что хотят или вовсе не хотят знать о традициях своей культуры»; «Если бы не прошлое - не было бы будущего»; «Не только религиозный опыт формирует личность»; «Большевиков ожидал крах из-за отношения к церкви»; «Православное государство никогда не будет лидером»; «Необходимо изу- 
чать такие курсы на протяжении всего школьного и вузовского периода»; «Российская империя - это нерушимый, объединенный центр, который является мощной опорой для многих государств»; «Православие - символ единения»; «Именно познание национальной культуры делает человека “культурным”»; «Мы должны уважать свою культуру, традиции, свою веру - именно вследствие этого складывается укрепленное и сильное во всех сферах государство»; «Человек, который чтит свои традиции, с уважением будет относиться к другим культурам»; «Каждый человек должен познать духовность своего народа. Она развивает и расширяет его кругозор и дает понять сущность русского народа, его обычаи»; «Без знаний о русской культуре будет невозможно осознать многие другие предметы»; «Именно на нашу страну ее прошлое повлияло в большей степени»; «Религия всегда объединяла русский народ».

Как можно видеть, при всей сложности картины и многообразном спектре эмоционально окрашенных ценностных суждений, студенческая молодежь продолжает воспринимать историческое прошлое страны как живую часть культурного опыта современного российского социума, признавая духовное и художественное наследие своеобразной гарантией развития исторического самосознания - условием движения к будущему. Можно говорить, что в последние 10 лет эта тенденция развивается с общей линией государственной культурной политики по восстановлению исторической преемственности и сохранению культурного наследия.

\section{ЦЕННОСТИ ИСТОРИИ И КУАЬТУРЫ \\ В МУАЬТИМЕАИЙНОМ ФОРМАТЕ}

Озаботившись вопросом национально-культурной идентичности российского общества и молодого поколения, власть в образовательных и просветительских целях активно использует современный инструментарий мультимедиа. Государство привлекает к историческим проектам ученых и представителей Русской православной церкви. Музейно-выставочные пространства с развернутыми на них грандиозными выставками становятся лабораторными площадками по выработке общенациональной идеи. Примером являются две интерактивных выставки-форумы «Православная Русь. Романовы», посвященная 400-летию дома Романовых (2013) и «Моя история. Рюриковичи» (2014) в Центральном выставочном зале «Манеж». Успех выставок способствовал продолжению идеи тематической репрезентации российской истории в мультимедийном выставочном формате. Проект увенчался открытием в начале 2016 г. в обновленном павильоне № 57 на ВАНХ исторического парка «Россия - моя история», вобравшем в себя конструктивные и содержательные элементы ранее состоявшихся выставок.

Стоит отметить появление еще одного важного инструмента, участвующего в процессе актуализации отечественной истории, - это телевидение и Интернет. Цели и ценности, разделяемые авторами телевизионных передач и многообразных интернет-сайтов с исторической, социально-политической и религиозно-культурной тематикой, посвященной России, могу быть различными, как и их политические и религиозные взгляды. Но эти востребованные зрителями и пользователями Интернета формы репрезентации исторического предания в публичном пространстве отражают важнейший социальный и ментальный процесс - процесс формирования культурно-политической нации. 
В этом контексте может быть интерпретирована идейная сверхзадача специализированного телевизионного канала «История». Он начал вещание 9 мая 2013 г. в символическую дату для всех россиян, объединяющую нацию на основе патриотического консенсуса и памяти о войне, дополнив серию цифровых каналов ВГТРК познавательного характера. Идея канала определяется девизом: «Телеканал "История" берется доказать: история - это ярко, интересно, интригующе и познавательно» (О телеканале: Электронный ресурс). «Философия телеканала "История", - сообщается на сайте телеканала, - это самый широкий взгляд на эволюцию человечества: от древнейших цивилизаций и великих открытий прошлого до величайших загадок и тайн настоящего, а также великие войны и победы, великие люди, великая любовь и предательство - все то, что делает историю интересной и увлекательной. Программное наполнение телеканала состоит из продуктов собственного производства и лучших зарубежных форматов крупнейших мировых студий» (там же).

Обращает на себя внимание, что в линейке канала четыре специальных цикла посвящены истории России. Среди них - цикл «Символы России», рассказывающий о достижениях российской цивилизации, «История России в орденах», «История СССР. Как это было» и программа «Русский мир» - о вкладе наших соотечественников в культуру и историю. Заметно стремление авторского коллектива канала интегрировать советский период в большое время истории Руси/России, найти ценностные и идейно-политические основания для стягивания различных историко-культурных эпох в единый нарратив. Тем самым телеканал, помимо познавательных и научно-просветительских задач, выполняет и общественно-политический заказ на формирование исторического канона, могущего послужить основой единого учебника истории.

\section{ЗАКАЮЧЕНИЕ}

Безусловно, выставочные и телевизионные опыты реконструкции отечественной истории, о которых шла речь, можно оценить положительно, принимая во внимание и творческий потенциал современных медиа, и охват аудитории, которой предлагается просветительский и познавательный контент. Однако задача неангажированного изучения духовно-культурного и политического опыта России в условиях явной приватизации публичного пространства доминантной группой властных элит становится еще более насущной в первую очередь для профессиональных кругов и гражданского общества. Только с их участием новый нарратив истории сможет взять на себя роль культурного предания, вокруг которого должен выстраиваться новый общественный договор - согласие нации по поводу прошлого, настоящего и будущего России. Работа по осмыслению отечественной истории и культуры в контексте мировой должна стать актом самопознания и интеллектуальной рефлексии современного российского общества, что позволит изучать прошлое в перспективе будущего и «перезагрузить» процесс культурной самоидентификации на основе ценностного консенсуса.

\section{ПРИМЕЧАНИЕ}

${ }^{1}$ История - верная свидетельница прошлого, свет истины, жизнь памяти, учительница жизни, вестница старины (лат). 


\title{
СПИСОК АИТЕРАТУРЫ
}

Бауман, 3. (2005) Индивидуализированное общество : пер. с англ. М. : Аогос. 390 с.

Грановский, Т. Н. (2010) Публичные чтения. Статьи. Письма / сост. А. А. Аевандовский, А. А. Цыганков. М. : Российская политическая энциклопедия. 672 с.

Жукова, О. А. (2006) История русской культуры и современность // Вопросы истории. № 8. C. 105-116.

Жукова, О. А. (2007) История русской культуры в вузе: историческое знание и духовная традиция // Вопросы истории. № 8. С. 1-10.

Жукова, О. А. (2008) Как изучать русскую культуру? Гуманитарная стратегия в системе вузовского образования // Вопросы культурологии. № 9. С. 42-45.

Иотман, Ю. М. (2004) Семиосфера. СПб. : Искусство-СПб. 704 с.

O телеканале [Электронный ресурс]// Телеканал «История». URL: http://istoriya.tv/ index (дата обращения: 11.04.2016).

Аата поступления: 02.06. 2016 2.

\author{
THE CHOICE OF VALUES \\ IN RUSSIAN SOCIETY AS A PROBLEM \\ OF CULTURAL IDENTITY \\ O. A. ZHUKOVA \\ (National Research University Higher School \\ OF ECONOMICS)
}

The article deals with the issue of historical self-understanding of contemporary Russian society. A nation's civilization-wise self-determination is formed through mastering national history and learning the lessons of the social catastrophes of the 20th century. It is possible to transmit the social experience of the past to new generations by actualizing cultural values originally born within Russia's religious, artistic and political traditions. Russian society should expand its discursive practices of cultural and historical knowledge, together with the sphere of public discussion of history and culture. This article looks at two potential implications (educational and cultural) of the current state of affairs.

Especially urgent is the issue of how the younger generation imagines and understands themselves, of the values they share, their attitudes to the history of Russia and the various types of ethnic heritage. We present the outcomes of a sociological study held by the author for 6 years (2006-2012) while teaching freshmen at the Institute of Economics and Industrial Management, National University of Science and Technology MISiS. The study clearly showed that today's students, like the previous generations, perceive Russia's historical past as a living part of the contemporary society's experience. They see the country's spiritual and artistic heritage as a certain safeguard of historical conscience and a precondition for its future development.

In the last decade this trend has been aligned with the federal cultural policy and its focus on rebuilding historical continuity and preserving cultural heritage. Thus we analyze the current federal policy in the spheres of culture and education, the educational use of cutting-edge multimedia tools and the topical forms of structuring exhibition and museum space in order to transform them into intellectual platforms for working out a national idea. Debates on such issues as interpretations of history, the perspectives of a single history textbook for secondary schools, mark the 'trigger points' of the nation's historical well-being.

Keywords: choice of values; Russian society; cultural self-identification; cultural memory; cultural lore; historical experience 


\section{REFERENCES}

Bauman, Z. (2005) Individualizirovannoe obshchestvo. Moscow, Logos. 390 p. (In Russ.).

Granovskii, T. N. (2010) Publicbnye chtenija. Stat' i. Pis' ma, comp. A. A. Levandovskii and D. A. Tsygankov. Moscow, Rossiiskaja politicheskaia entsiklopediia. 672 p. (In Russ.).

Zhukova, O. A. (2006) Istoriia russkoi kul'tury i sovremennost'. Voprosy istorii, no. 8, pp. 105-116. (In Russ.).

Zhukova, O. A. (2007) Istoriia russkoj kul'tury v vuze: istoricheskoe znanie i dukhovnaia traditsiia. Voprosy istorii, no. 8, pp. 1-10. (In Russ.).

Zhukova, O. A. (2008) Kak izuchat' russkuiu kul'turu? Gumanitarnaia strategiia v sisteme vuzovskogo obrazovaniia. Voprosy kul' turologii, no. 9, pp. 42-45. (In Russ.).

Lotman, Yu. M. (2004) Semiosfera. St. Petersburg, Iskusstvo-SPb. 704 p. (In Russ.).

O telekanale. Telekanal «Istoriia» [online] Available at: http://istoriya.tv/index (access date: 11.04.2016). (In Russ.).

Submission date: 02.06.2016.

Жукова Ольга Анатольевна - доктор философских наук, кандидат культурологии, профессор Школы философии факультета гуманитарных наук Национального исследовательского университета «Высшая школа экономики». Адрес: 105066, Россия, г. Москва, ул. Старая Басманная, д. 21/4. Тел.: +7 (495) 772-95-90. Эл. aдpec: logoscultura@yandex.ru

Zhukova Olga Anatol'evna, Doctor of Philosophy, Candidate of Culturology, Professor, School of Philosophy, Faculty of Humanities, National Research University Higher School of Economics. Postal address: 21/4 Staraya Basmannaya St., 105066 Moscow, Russian Federation. Tel.: +7 (495)772-95-90. E-mail: logoscultura@yandex.ru 